\title{
Observation operator for the assimilation of aerosol type resolving satellite measurements into a chemical transport model
}

\author{
M. Schroedter-Homscheidt ${ }^{1}$, H. Elbern ${ }^{2, *}$, and T. Holzer-Popp ${ }^{1}$ \\ ${ }^{1}$ Deutsches Zentrum für Luft- und Raumfahrt e.V., Oberpfaffenhofen, Germany \\ ${ }^{2}$ Rhenish Institute for Environmental Research at the University of Cologne, Köln, Germany \\ *now at: ICG-2, Forschungszentrum Jülich, Germany
}

Received: 17 March 2010 - Published in Atmos. Chem. Phys. Discuss.: 7 June 2010

Revised: 28 September 2010 - Accepted: 2 October 2010 - Published: 8 November 2010

\begin{abstract}
Modelling of aerosol particles with chemical transport models is still based mainly on static emission databases while episodic emissions cannot be treated sufficiently. To overcome this situation, a coupling of chemical mass concentration modelling with satellite-based measurements relying on physical and optical principles has been developed. This study deals with the observation operator for a component-wise assimilation of satellite measurements. It treats aerosol particles classified into water soluble, water insoluble, soot, sea salt and mineral dust containing aerosol particles in the atmospheric boundary layer as separately assimilated aerosol components. It builds on a mapping of aerosol classes used both in observation and model space taking their optical and chemical properties into account. Refractive indices for primary organic carbon particles, anthropogenic particles, and secondary organic species have been defined based on a literature review. Together with a treatment of different size distributions in observations and model state, this allows transforming the background from mass concentrations into aerosol optical depths. A two-dimensional, variational assimilation is applied for component-wise aerosol optical depths. Error covariance matrices are defined based on a validation against AERONET sun photometer measurements. Analysis fields are assessed threefold: (1) through validation against AERONET especially in Saharan dust outbreak situations, (2) through comparison with the British Black Smoke and
\end{abstract}

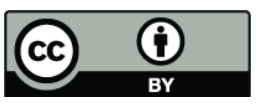

Correspondence to: M. Schroedter-Homscheidt (marion.schroedter-homscheidt@dlr.de)
Sulphur Dioxide Network for soot-containing particles, and (3) through comparison with measurements of the water soluble components $\mathrm{SO}_{4}, \mathrm{NH}_{4}$, and $\mathrm{NO}_{3}$ conducted by the EMEP (European Monitoring and Evaluation Programme) network. Separately, for the water soluble, the soot and the mineral dust aerosol components a bias reduction and subsequent a root mean square error reduction is observed in the analysis for a test period from July to November 2003. Additionally, examples of an improved analysis during wildfire and dust outbreak situations are shown.

\section{Introduction}

Both, global and regional chemical transport modelling (CTM) have successfully included aerosol modules in recent years (Binkowski, 1999; Ebel, 1997a; Rasch et al., 2000; Chin et al., 2002). Apart from scientific research questions this is motivated mainly by the implications of aerosols on human health and the radiative budget in the atmosphere. While the modelling of physical and chemical processes has improved widely, a specific problem is the timely information of special events with elevated aerosol emissions. Typically, databases show deficiencies in spatial and temporal resolution, quantitative values and their evolution over time (Memmesheimer et al., 2004). Irregular episodic events like fires or variable sources in transportation or vegetation cannot be modelled on this basis. Additionally, dust source region databases are typically not detailed enough in terms of spatial resolution and mineral dust size distribution (Engelstaedter et al., 2006). Together with uncertainties in the

Published by Copernicus Publications on behalf of the European Geosciences Union. 
modelled wind and surface stress fields this results in deficiencies in modelling dust outbreaks as another class of episodic aerosol events.

Therefore, up to date measurements have to be taken into account using data assimilation methods. Ground measurements often show a confined geographical coverage which is insufficient compared to the typical horizontal aerosol source variability. Satellite-based sensors provide aerosol measurements on a regional or global scale, covering larger areas within a single overpass. Currently, all satellite-based algorithms provide aerosol optical depth (AOD) observations. Therefore, a coupling between the chemical descriptions in terms of mass concentrations used in air quality models and the physical properties observed by satellites has to be introduced (e.g. Hutchinson et al., 2004). In terms of data assimilation parlance, such a coupling is provided by the observation operator. Besides the spatio-temporal interpolation between a gridded CTM and the irregular distributed satellite observations, the observation operator couples between the different aerosol descriptions in the background model and the observations.

Data assimilation has been widely used in numerical weather prediction (e.g. Daley, 1991; Lorenc, 1986) and oceanography (Ghil, 1989), and since the nineties it has been extended towards chemical transport modelling (Elbern et al., 1997, 2001, 2007; Jeuken et al., 1999; Khattatov et al., 1999; Lahoz et al., 2007a, b; Lamarque et al., 1999; Levelt et al., 1998; van Loon et al., 2000). Most of these studies deal with the assimilation of gas phase species as e.g. ozone, nitrogen dioxide or carbon monoxide.

First assimilation studies of satellite based AOD observations have been presented in recent years. During the Indian Ocean Experiment (INDOEX) Collins et al. (2001) used an optimum interpolation method to assimilate AOD observations made by the AVHRR (Advanced Very High Resolution Radiometer) instrument into the Model of Atmospheric Transport and Chemistry (MATCH, Rasch et al., 1997). Due to missing aerosol type information in the observations and the focus of INDOEX on the distribution of maritime aerosols (Rasch, 2001), this study assumes a fixed aerosol type based on optical properties of maritime aerosols. An equivalent approach has been used by Yu et al. (2003) to assimilate AOD observations of the Moderate Resolution Imaging Spectroradiometer (MODIS) into the Goddard Global Ozone Chemistry Aerosol and Transport (GOCART) model. Verver et al. (2002) and van Velthoven et al. (2004) present an assimilation of Along Track Scanning Radiometer (ATSR-2) observations into the chemical tracer model TM3, also based on a similar approach.

While all these studies assume a constant aerosol type for all observations independent of the regional aerosol composition, there are also studies focusing on the assimilation of observations representing a single aerosol component. Wang et al. (2004a, b) assimilate dust aerosol observations taken selectively by the Geostationary Operational
Environmental Satellite (GOES-8, Wang et al., 2003) over the Atlantic Ocean. For the Puerto Rico Dust Experiment (PRIDE) in July 2000 a nudging approach was used to assimilate these GOES- 8 observations into the Regional Atmospheric Modelling System (RAMS). Niu et al. (2008) use a variational approach for the assimilation of a dust index provided by the geostationary FY-2C satellite into the Chinese Unified Atmospheric Chemistry Environment - Dust (CUACE/Dust) forecast system. Also, in a case study covering East Asia in May 2007, Hara et al. (2009) use observations of the Cloud Aerosol Lidar with Orthogonal Polarization (CALIOP) to simulate dust outbreak events over China and Japan within the RAMS/CFORS (Regional Atmospheric Modeling System/Chemical weather FORecast System) dust transport model.

A first assimilation of aerosol size distribution resolving observations was published by Generoso et al. (2007) using "fine" and "coarse mode" observations made over the Arctic by the POLarization and Directionality of the Earth's Reflectances (POLDER) instrument and the LMDz-INCA (Laboratoire de Météorologie Dynamique Zoom-Interaction Chimie Aérosols) chemical transport model.

Meanwhile the Synergetic Aerosol Retrieval (SYNAER, Holzer-Popp et al., 2002a, b, 2008) provides aerosol optical depth observations from ENVISAT (Environmental Satellite) Advanced Along Track Scanning Radiometer (AATSR) and Scanning Imaging Absorption Spectrometer for Atmospheric CHartographY (SCIAMACHY) separately for the soot, mineral, water soluble, water insoluble and sea salt components. This opens the possibility to assimilate aerosols in a component-wise approach over both land and ocean.

This study focuses on the development of an observation operator for SYNAER observations with their separation of major aerosol components representative for the atmospheric boundary layer and the troposphere. This is a basis for an operational variational assimilation system of SYNAER observations provided by ENVISAT and in the future the Meteorological Operational Polar Satellites (METOP).

Section 2 provides a description of the study setup, the SYNAER observations with their underlying aerosol component definition, the European Air Pollution DispersionInverse Model (EURAD-IM) with its aerosol class definition and the validation data bases. Section 3 describes the concept and development of the observation operator together with a validation of both background model and observations as a basis of error covariance definition. Section 4 presents a validation of analysis fields both in terms of aerosol optical depth and mass concentrations against ground-based measurements. Finally, Sect. 5 concludes the paper with a discussion of its achievements and limitations. 


\section{Study setup}

The study is based on a test period from 1 July to 30 November 2003. It relies on the availability of three-dimensional mass concentration fields of all internal EURAD model aerosol classes, while the standard output of the operational EURAD model version provides only particulate matter with particles having a diameter above $10 \mu \mathrm{m}\left(\mathrm{PM}_{10}\right)$. Such a data set has been created for Europe as a result of the ASSET ("Assimilation of ENVISAT data", 2003-2006, Lahoz et al., 2007b) project.

\subsection{SYNAER measurements}

The synergetic aerosol retrieval method SYNAER (HolzerPopp et al., 2002a, b, 2008) delivers aerosol optical depth (AOD) at $550 \mathrm{~nm}$ over both land and ocean and an estimation of the aerosol type in the lower troposphere including a possible elevated dust layer. It exploits a spatially high resolving (typically $1 \mathrm{~km}^{2}$ ) radiometer allowing accurate cloud detection (Kriebel et al., 1989, 2003) and dark field aerosol assessment together with a spectrally high resolving spectrometer allowing aerosol type retrieval. The type of aerosol is estimated as percentage contribution to AOD of representative components from an extension of the OPAC (Optical Parameters of Aerosols and Clouds, Hess et al., 1998) dataset as described in Holzer-Popp et al. (2008).

The SYNAER aerosol retrieval algorithm comprises of two major parts: (1) A dark field method exploiting single wavelength radiometer reflectances $(670 \mathrm{~nm}$ over land, $870 \mathrm{~nm}$ over ocean) and (2) a least square fit of visible top-ofatmosphere reflectance spectra at 10 wavelengths $(415,428$, $460,485,500,516,523,554,615$, and $675 \mathrm{~nm}$ ) with the spectrometer. In the first step, AOD over automatically selected and characterized dark pixels is derived and subsequently a surface albedo correction at 550,670, and $870 \mathrm{~nm}$ is done with the radiometer. The knowledge of atmospherically corrected spectral surface albedo is further used for a characterization of the surface type. This first step is repeated for 40 different pre-defined aerosol mixtures. After spatial integration of the results (40 AOD, 120 surface reflectance values for 40 mixtures times 3 AATSR wavelengths, 40 surface types) to the larger pixels of the spectrometer $\left(60 \times 30 \mathrm{~km}^{2}\right)$, these parameters are used in the second step to simulate 40 spectra for the same set of 40 different aerosol mixtures using the same radiative transfer code. A least square (LSQ) fit of measured reflectances $R_{\text {meas }}$ for all $l$ wavelengths $(l=10)$ vs. simulated reflectances $R_{j}$ for the $j-$ th aerosol mixture

$\mathrm{LSQ}_{j}=\sum_{l=1}^{10}\left(R_{\lambda_{l}, \text { meas }}-R_{\lambda_{l}, j}\right)^{2}$

provides the correct AOD value as the AOD for the selected aerosol mixture with a minimum LSQ and - if a uniqueness test as described in Eq. (11) is passed - the plausible aerosol mixture. Only pixels with a retrieved aerosol mixture are used in this study dealing with an aerosol component wise assimilation approach. All radiative transfer calculations within SYNAER assume spherical particles and Mie theory.

The entire method uses the same basic aerosol components (Holzer-Popp et al., 2008, Table 1). These components, their optical features and log-normal size distribution are taken from the OPAC database (Hess et al., 1998) for the water soluble (WASO), the water insoluble (INSO), the sea salt accumulation and coarse mode (SSAM and SSCM), and the mineral transported (MITR) component. On the basis of more recent campaigns and AERONET (Aerosol Robotic Network) data some specific items have been updated. The soot component is split in two components for strongly absorbing diesel soot (DISO) more representative for industrial areas and weakly absorbing biomass burning soot (BISO). For mineral dust an additional component for mineral dust with low absorption (MILO) represents dust sources with lower hematite content. As the insoluble component in OPAC (INSO) is modelled with the identical refractive index as the mineral transported component MITR, an insoluble component with low absorption (INSL) is also included.

These basic components are externally mixed into 40 different aerosol types meant to cover a realistic range of atmospheric aerosol masses (see details in Holzer-Popp et al., 2008). For humidity dependent components two models with $50 \%$ and $80 \%$ relative humidity are included. In the case of desert dust outbreaks, an elevated dust layer is added in the free troposphere.

SYNAER is applied to the radiometer AATSR and the spectrometer SCIAMACHY onboard ENVISAT resulting in a pixel size of $60 \times 30 \mathrm{~km}^{2}$. The measurement is taken daily at approximately 10:00 local time. Global coverage is achieved every 12 days, but cloud cover above $50 \%$ also reduces the number of available retrievals. The number of observations in SYNAER version 1.8 allows the evaluation of an assimilation scheme as presented in this study. Nevertheless, it is expected that an operational and sequential assimilation of SYNAER observations will only be meaningful for future METOP based SYNAER retrievals with a global coverage every $1-2$ days.

\subsection{The EURAD model}

The European Air Pollution Dispersion Model (EURAD, Ebel, 1989, 1997a, b; Memmesheimer et al., 2004; Builtjes et al., 2003; Elbern et al., 2007) consists of several coupled modules. Meteorological parameters are provided by the mesoscale model MM5 (Grell et al., 1994). The Modal Aerosol Dynamics model (MADE, Ackermann et al., 1998) provides aerosol dynamics and chemistry. Secondary aerosols and their precursor substances are described in the Secondary Organic Aerosol Module (SORGAM, Schell 
et al., 2001) and emissions are provided in the EuradEmissions-Model (EEM, Memmesheimer et al., 1995) based on existing databases. The National Center for Environmental Protection Global Forecast System (NCEP-GFS) analyses are used as meteorological driver for initial and boundary conditions. EURAD provides forecasts of the temporal and spatial distribution of atmospheric species both in the gas and in the particle phase. Explicitly modelled processes are horizontal and vertical advection, turbulent diffusion, dry and wet deposition, sedimentation, coagulation in and between nucleation and accumulation modes, condensation and nucleation of gas phase precursor substances, and particle emission.

For this study EURAD is used on the European scale with a horizontal grid box size of $56 \mathrm{~km}$. EURAD can also be operated on horizontal resolutions ranging from the hemispheric scale down to regional and urban scales with horizontal grid box sizes down to $1 \mathrm{~km}$. EURAD is operated with 23 layers between the surface and $15 \mathrm{~km}$ height and provides $\mathrm{PM}_{10}$ and $\mathrm{PM}_{2.5}$ (particulate matter with particle diameter less than $2.5 \mu \mathrm{m}$ ) as standard output. The MADE module internally provides mass concentrations of $\mathrm{SO}_{4}, \mathrm{NH}_{4}, \mathrm{NO}_{3}$, primary organic carbon, elemental carbon and anthropogenic primary fine mode particles both in the nucleation and accumulation mode. An additional anthropogenic aerosol class is described in the coarse particle mode. The SORGAM module adds mass concentrations in the nucleation and accumulation mode for secondary organic species resulting from anthropogenic and biogenic aromates, alkanes, alkenes, $\alpha$-pinene and d-limonene as precursor substances.

Primary aerosol particle emissions are based on a European emission database developed by the Nederlandse Organisatie voor toegepaast-natuurwetenschappelijk onderzoek (TNO, Berdowski et al., 1996) and updates within the Co-ordinated European Programme on Particulate Matter Emission Inventories (available at: http://www.air.sk/tno/ cepmeip). This database provides emission data for carbon monoxide, $\mathrm{PM}_{10}$ and $\mathrm{PM}_{2.5}$ particles based on the reference year 1995 in a horizontal resolution of $1 \times 0.5^{\circ}$. Anthropogenic sources as for example combustion in different power plant types, several industrial production and combustion processes, use of petrol and diesel in motor vehicles, tire abrasion, agricultural production, heating in private households, and waste combustion are taken into account. The database relies on use and production statistics, population databases as well as on agricultural food production statistics from a variety of international organisations. Additionally, the EEM model uses population databases and a weekly and daily variation distinguishing between working and weekend day emission levels.

EURAD as a modal model describes aerosol particles as separate log-normal size distributions in the nucleation, accumulation and coarse mode. Following Whitby et al. (1978) and Ackermann (1998) the partial differential equations are solved for the integral moments as prognostic variables. The size distributions' moments represent the total particle number and the aerosol particle volume. The size distribution width is kept constant during the model run, while the particle mass and number concentration are changed by physical and chemical processes. Within each mode the aerosol particles are modelled as an internal mixture.

Maritime and mineral aerosol components are not included in the EURAD version used for this study. Tegen et al. (1994) report on a European seasonal mean modelled dust AOD based on the NASA-GISS model below 0.05 for the seasons September to November and December to February, while mean AOD increases in summer to values up to 0.1 for March to May and June to August. For sea salt Tegen et al. (1997) report an annual average AOD below 0.08 for Europe. Generally, it has to be noted that dust events have a typical duration of a few days, occur typically at 5-7\% of days in Europe and cause typical mean AOD values in dust cases of up to 0.25 as identified by AERONET and lidar measurements (e.g. Meloni et al., 2007; Papayannis et al., 2008). Individual dust outbreaks reach values between 0.2 and 0.5 in Italy and Greece, while stations like Leipzig or Kühlungsborn in Germany observe values up to 0.27 and 0.13 , respectively. A comparison against SYNAER observations in the study period shows an underestimation of the total aerosol optical depth between -0.01 and -0.1 in $25 \%$ of 24747 coincidences over Europe, while an underestimation between -0.1 and -0.2 is found in $7 \%$ of all cases and a larger underestimation is found in 3\% of all cases. It has to be noted that since the ASSET project - which provided the model run used in this study in 2004 - the EURAD model has been extended by an explicit dust modelling scheme following Nickovich et al. (2001) and a sea salt scheme following Monahan et al. (1986).

\subsection{AERONET ground measurements}

AERONET (AErosol RObotic NETwork, http://aeronet.gsfc. nasa.gov) ground-based sun photometer measurements (Holben et al., 1998) are used for AOD validations at $550 \mathrm{~nm}$. AERONET is a global network with approx. 200 permanent stations, while this study is based on 47 stations providing version 2 datasets for Europe. Level 1.5 datasets include automatic cloud detection, while level 2 datasets are additionally checked for cloud occurrence manually. AERONET stations at Erdemli (Turkey, close to mountains), Palaiseau and Fontainebleau (France, greater Paris area), Rome Tor Vergata (Italy, next to a busy traffic crossing) and Hamburg (Germany, close to the coastline) are explicitly excluded as these stations are not representative for their surroundings on a satellite pixel or grid box scale. The overall uncertainty of AERONET AOD values in cloud-free conditions is \pm 0.01 for wavelengths down to $440 \mathrm{~nm}$ and \pm 0.02 for shorter wavelengths. 
Table 1. Optical characteristics of basic components used for external mixing in SYNAER (Holzer-Popp et al., 2008).

\begin{tabular}{|c|c|c|c|c|c|}
\hline $\begin{array}{l}\text { component } \\
\text { (rH= relative } \\
\text { humidity) }\end{array}$ & species & $\begin{array}{l}\text { complex } \\
\text { refract. index } \\
\text { at } 550 \mathrm{~nm}\end{array}$ & $\begin{array}{l}\text { mode radius } \\
{[\mu \mathrm{m}]}\end{array}$ & $\begin{array}{l}\text { stand. dev. of } \\
\text { size distribution }\end{array}$ & $\begin{array}{l}\text { literature } \\
\text { source }\end{array}$ \\
\hline $\begin{array}{l}\text { WASO, } \\
\mathrm{rH}=70 \%\end{array}$ & $\begin{array}{l}\text { sulfate/nitrate, water } \\
\text { soluble }\end{array}$ & $1.53-0.0055 \mathrm{i}$ & 0.028 & 2.24 & Hess et al., 1998 \\
\hline INSO & $\begin{array}{l}\text { insoluble particles, } \\
\text { absorption as MITR }\end{array}$ & $1.53-0.008 \mathrm{i}$ & 0.471 & 2.51 & Hess et al.,1998 \\
\hline INSL & $\begin{array}{l}\text { insoluble particles, } \\
\text { low absorption }\end{array}$ & $1.53-0.0019 \mathrm{i}$ & 0.471 & 2.51 & Dubovik et al., 2002 \\
\hline $\begin{array}{l}\text { SSAM, } \\
\mathrm{rH}=70 \%\end{array}$ & $\begin{array}{l}\text { sea salt, } \\
\text { accumulation mode }\end{array}$ & $1.49-0 \mathrm{i}$ & 0.378 & 2.03 & Hess et al., 1998 \\
\hline $\begin{array}{l}\text { SSCM, } \\
\mathrm{rH}=70 \%\end{array}$ & $\begin{array}{l}\text { sea salt, } \\
\text { coarse mode }\end{array}$ & $1.49-0 \mathrm{i}$ & 3.17 & 2.03 & Hess et al., 1998 \\
\hline BISO & biomass burning soot & $1.63-0.036 \mathrm{i}$ & 0.0118 & 2.0 & Dubovik et al., 2002 \\
\hline DISO & diesel soot & $1.49-0.67 \mathrm{i}$ & 0.0118 & 2.0 & Schnaiter et al., 2003 \\
\hline MITR & $\begin{array}{l}\text { transported minerals, } \\
\text { high hematite content }\end{array}$ & $1.53-0.0055 \mathrm{i}$ & 0.5 & 2.2 & Hess et al., 1998 \\
\hline MILO & $\begin{array}{l}\text { transported minerals, } \\
\text { low hematite }\end{array}$ & $1.53-0.0019 \mathrm{i}$ & 0.5 & 2.2 & Dubovik et al., 2002 \\
\hline
\end{tabular}

\subsection{British Black Smoke and Sulphur Dioxide Network}

The UK Black Smoke and Sulphur Dioxide Network (Loader et al., 2003; http://www.airquality.co.uk) measures both the black smoke concentrations and the atmospheric $\mathrm{SO}_{2}$ equivalent of all atmospheric acids as a daily mean at 137 stations in the United Kingdom. Most stations are representing urban background or suburban conditions, but there are also background stations available. A black smoke index is derived by a reflectometer measurement of a darkened filter after $24 \mathrm{~h}$ exposition time. This is post processed to black smoke mass concentrations following the "British Standard Smoke Calibration Curve". Mass concentrations of black smoke can be set equal to mass concentrations of elementary carbon as organic carbon on the filter does not contribute to the blackness of the filter. For typical mass concentrations in the UK, an uncertainty of $30 \%$ is reported.

\subsection{EMEP network}

The Co-operative Programme for Monitoring and Evaluation of the Long-range Transmission of Air pollutants in Europe with its European Monitoring and Evaluation Programme (EMEP, http://www.emep.int) focuses on the chemical composition of gas, particle and liquid phases in the atmosphere. 48 countries are contributing with $\mathrm{PM}_{10}$ and $\mathrm{PM}_{2.5}$ measurements. Overall, 16 in-situ stations in Hungary, Italy, Lithuania, the Netherlands, Norway, Poland, Russia and Turkey provide separate daily mean measurements of $\mathrm{SO}_{4}, \mathrm{NH}_{4}$ and $\mathrm{NO}_{3}$ based on ion chromatography. These can be compared with mass concentrations as modelled in EURAD. The uncertainty requirement is set at $10 \%$ or better (EMEP, 2001).

\section{The observation operator}

\subsection{Two-dimensional variational assimilation}

Most data assimilation procedures are based on an optimisation strategy, employing a least square minimisation (e.g. Daley, 1991; Bouttier and Courtier, 1999) and solve the analysis equations

$\boldsymbol{x}_{a}=\boldsymbol{x}_{b}+\mathbf{K}\left(\boldsymbol{y}_{o}-\mathbf{H} \boldsymbol{x}_{b}\right)$

$\mathbf{K}=\mathbf{B H}^{T}\left(\mathbf{H B H}^{T}+\mathbf{R}\right)^{-1}$

in order to provide a best linear and unbiased estimator (BLUE). The model state for a specific time is given by the vector $\boldsymbol{x}$. The model background state, forecast or first guess field at the beginning of the assimilation process is given by $\boldsymbol{x}_{b}$, while $\boldsymbol{x}_{a}$ represents the analysis field at the end of the assimilation procedure. Observations are represented in the vector $\boldsymbol{y}_{o}$, while $\mathbf{R}$ describes the observation error covariance matrix. Matrix $\mathbf{B}$ is the background error covariance matrix. The observation operator $\mathbf{H}$ maps the model state $\boldsymbol{x}$ into observation space. Matrix K, the "Kalman gain matrix", 
describes the weights attributed to the observation increment, given by $\left(\boldsymbol{y}_{o}-\mathbf{H} \boldsymbol{x}_{b}\right)$.

Generally in assimilation theory, the observation operator $H$ is non-linear. In our case the optimization is made with respect of particle number and not with respect to the particle diameter distribution. Therefore, $\mathbf{H}$ becomes a linear operator as the Mie theory is applied.

In order to achieve the BLUE characteristics an efficient observation quality control is needed to exclude outliers (see Sect. 3.3.1), both background and observations should be free from systematic errors (discussed in Sects 3.3 and 5 for this case) and errors in background and observations should be uncorrelated. The latter assumption is justified as the satellite observations are retrieved independently from the chemical transport modelling.

Both two- and three-dimensional variational assimilation methods define a cost function $J$ as

$$
\begin{aligned}
J(\boldsymbol{x})= & \frac{1}{2}\left(\boldsymbol{x}-\boldsymbol{x}_{b}\right)^{T} \mathbf{B}^{-1}\left(\boldsymbol{x}-\boldsymbol{x}_{b}\right) \\
& +\frac{1}{2}\left(\boldsymbol{y}_{o}-\mathbf{H} \boldsymbol{x}_{b}\right)^{T} \mathbf{R}^{-1}\left(\boldsymbol{y}_{o}-\mathbf{H} \boldsymbol{x}_{b}\right)
\end{aligned}
$$

The analysis $\boldsymbol{x}_{a}$ is a solution of the minimization problem for $J$, where the analysis increment $\Delta \boldsymbol{x}_{a}$ is defined as $\left(\boldsymbol{x}_{a}-\boldsymbol{x}_{b}\right)$.

Chemical transport models like EURAD provide mass concentrations of a large number of aerosol classes or the particle diameter integrated $\mathrm{PM}_{10}$ mass parameter as a standard output. Having aerosol component resolving SYNAER observations, the assimilation in $\mathrm{PM}_{10}$ space would not use this component-wise information. Rather, EURAD mass concentrations are provided on 23 vertical layers and for 29 internal aerosol classes, which is much more detailed information than provided by the SYNAER total column AOD observations provided for 9 different components. Therefore, assimilation of AOD space is chosen to reduce complexity and computational time. As AOD observations are vertically integrated geophysical parameters, the three dimensions used in 3-D-Var methods are reduced to two dimensions (2-D-Var) only.

As a preprocessing step the separation of $A_{\text {OOD }}$ total, $550 \mathrm{~nm}$ in the component-wise AOD of SYNAER basic components according to their percentage contribution $f_{j}$ in each aerosol mixture is needed (Table 1)

$y_{j}=f_{j} \mathrm{AOD}_{\text {total,550 }} \mathrm{nm} \quad j=1$, number of components

For the acceptance as spatio-temporal coincidences between observations and local model states, ENVISAT observations within $\mathrm{a} \pm 2 \mathrm{~h}$ window around analysis time (in this study taken at 10 UTC) are taken into account.

The following steps are needed in the assimilation procedure:

\section{(A) Observation operator $\mathbf{H}$}

Mapping of vertically resolved mass concentrations $\boldsymbol{x}_{b}$, mass of all EURAD aerosol classes in all modes (model state) into a vertically integrated $\mathrm{AOD}_{550 \mathrm{~nm}}$ for each of the $j$ SYNAER components $\left(\boldsymbol{x}_{b}, \mathrm{AOD}, j\right)$ following Table 2 .

$\boldsymbol{x}_{b, \mathrm{AOD}, j}=\int_{k=1}^{k_{\max }} \sum_{i} \int_{0}^{\infty} C_{\mathrm{ext}, \mathrm{k}, \mathrm{i}}\left(D_{k, i}, m_{k, i}\right) \frac{d N_{k, i}}{d \ln D} d \ln D d z(5)$

The index $i$ represents a size mode contributing to one of the $j$ components, $k$ represents the index of a vertical layer, $C_{\text {ext }}$ describes the extinction cross section of a particle as a function of particle diameter $D$ and complex refractive index $m, N_{k, i}$ denotes the total particle number in mode $i$ and layer $k$, while $z$ represents height. Section 3.2 describes this step in more detail.

The extinction efficiency $Q_{\text {ext }}$ is calculated using a fast parameterisation of the Mie theory as suggested by Evans and Fournier (1990). This parameterisation combines both the Rayleigh approximation for small particles and the Van de Hulst approximation for large particles with an empirical formula based on explicit Mie calculations. Following Evans and Fournier, the deviation from explicit Mie calculation is below $1 \%$ by variation of the real part of the refractive index between 1.01 and 2.0 and the imaginary part between 0 and 10. The approximation deficiency can be neglected compared to other uncertainties like in refractive indices introduced by assumptions on the aerosol composition. The parameterisation reduces the computational expenditure by approximately a factor of 30 and allows the use of Mie theory for an operational application.

\section{(B) 2-D-Var minimization}

A 2-D-Var minimization and derivation of analysis increments is applied for each SYNAER components.

$\Delta \boldsymbol{x}_{a, \mathrm{AOD}}=\mathbf{K}\left(\boldsymbol{y}_{o}-\mathbf{H} \boldsymbol{x}_{b}\right.$, mass $) \quad \forall$ components

In this study, the 2-D-Var assimilation is done separately for the water soluble component (WASO), the insoluble component (sum of SYNAER INSO and INSL) and the soot component (sum of SYNAER BISO and DISO). All components are represented by two-dimensional aerosol optical depth fields. Later in operations this step will be conducted also for the mineral component (sum of SYNAER MITR and MILO) and the sea salt component (sum of SYNAER SSAM and SSCM) as the EURAD model has meanwhile been extended by a dust and sea salt module.

The cost function is minimized using a L-BGFS (Limited memory Broyden-Fletcher-Goldfarb-Shanno) quasi Newton method, adopted from Liu and Nocedal (1989).

Background and observation error covariance matrices are initially set as diagonal with constant values of $(0.12)^{2}$ for observations and $(0.3)^{2}$ for the model background based on validation results as discussed in Sect. 3.3. A componentwise definition of covariance matrices is not possible due to the lack of component-wise AOD ground measurements. 
Table 2. Mapping of EURAD aerosol classes to SYNAER aerosol components together with the refractive index chosen for EURAD aerosol classes.

\begin{tabular}{|c|c|c|}
\hline $\begin{array}{l}\text { EURAD aerosol } \\
\text { class }\end{array}$ & $\begin{array}{l}\text { refractive index set } \\
\text { for EURAD class }\end{array}$ & $\begin{array}{l}\text { SYNAER aerosol } \\
\text { component }\end{array}$ \\
\hline sulphuric acid & $1.443+\mathrm{i} 0.0$ & water soluble (WASO) \\
\hline ammonium sulphate & $1.53+\mathrm{i} \times 10^{-7}$ & water soluble (WASO) \\
\hline ammonium nitrate & $1.53+\mathrm{i} 0.0$ & water soluble (WASO) \\
\hline nitric acid & $1.393+\mathrm{i} 0.0$ & water soluble (WASO) \\
\hline water & $1.333+\mathrm{i} 1.96 \times 10^{-9}$ & \\
\hline primary organic & $1.43+\mathrm{i} 0.0$ & insoluble (INSO and INSL) \\
\hline reaction products of aromatics & $1.55+\mathrm{i} 0.0$ & water soluble (WASO) \\
\hline reaction products of alkanes & $1.43+\mathrm{i} 0.0$ & water soluble (WASO) \\
\hline reaction products of alkenes & $1.45+\mathrm{i} 0.0$ & water soluble (WASO) \\
\hline reaction products of $\alpha$-pinen & $1.55+\mathrm{i} 0.0$ & water soluble (WASO) \\
\hline reaction products of limonen & $1.55+\mathrm{i} 0.0$ & water soluble (WASO) \\
\hline elementary carbon & $1.75+\mathrm{i} 0.44$ & $\begin{array}{l}\text { industrial soot (SOOT/DISO) } \\
\text { or biomass burning soot }\end{array}$ \\
\hline primary fine aerosol & $1.53+\mathrm{i} 0.08$ & $\begin{array}{l}\text { (SOOT/BISO) depending on location } \\
\text { insoluble (INSO and INSL) }\end{array}$ \\
\hline anthropogenic coarse mode & $1.53+\mathrm{i} 0.08$ & insoluble (INSO and INSL) \\
\hline $\begin{array}{l}\text { maritime aerosol } \\
\text { (in preparation) }\end{array}$ & $1.5+\mathrm{i} \times 10^{-8}$ & sea salt (SSAM and SSCM) \\
\hline $\begin{array}{l}\text { mineral dust } \\
\text { (in preparation) }\end{array}$ & $1.53+\mathrm{i} 0.0055$ & $\begin{array}{l}\text { transported mineral aerosol } \\
\text { (MITR and MILO) }\end{array}$ \\
\hline
\end{tabular}

Kokhanovsky et al. (2007) showed a 1\% agreement of the calibration among the ENVISAT instruments SCIAMACHY and MERIS (Medium Resolution Imaging Spectrometer). Therefore, we assume that there is no gross calibration error affecting all observations. Generally, aerosol retrieval schemes are ill-posed causing that pixel to pixel error correlations are negligible compared to other retrieval assumptions applied in the surface reflectance estimation and the aerosol model. Therefore and having in mind that this is a first assimilation study, observations are assumed to be uncorrelated to each other resulting in diagonal covariance matrices.

A diffusion approach described by Weaver and Courtier (2001) is applied to model the background error covariance matrix using the implementation as described in Elbern et al. (2007). Isotropic horizontal diffusion coefficients are used. Influence radii of the horizontal diffusion between 0.1 and 3 grid boxes around the observation's grid box (corresponding to values between 5 and $170 \mathrm{~km}$ with a grid box size of $56 \mathrm{~km}$ ) were tested following Anderson et al. (2003) who found a spatial AOD correlation length below $200 \mathrm{~km}$ in ground, aircraft and space-based measurements. Finally, the influence radius is set to 1.0 grid boxes $(56 \mathrm{~km})$ which is also in the range of the longer side of a SYNAER pixel $(60 \mathrm{~km})$.

\section{(C) Adjoint observation operator}

The adjoint observation operator is used to transfer the new model state $\boldsymbol{x}_{\mathbf{a}, A O D}$ from the SYNAER component AOD space into the vertically resolved mass concentrations of EURAD aerosol classes $\left(\boldsymbol{x}_{\mathbf{a}, \mathbf{A O D}}\right)$.

$\boldsymbol{x}_{a, \mathrm{mass}}=\mathbf{H}^{T} \boldsymbol{x}_{a, \mathrm{AOD}} \quad \forall$ mass concentrations

It has to be noted that both vertical profile and size distribution of the EURAD aerosol field are not changed by the assimilation as the observations do not provide such information independent from any further assumptions. Therefore, a factor $g$ based on the analysis increment in each aerosol component $j$ can be linearly applied to mass concentrations of all $i$ aerosol size modes mapped to an aerosol component $j$ (Table 2) in each vertical layer. This changes the overall amount of mass concentrations, but keeps the vertical structure of the aerosol profile and the distribution of aerosol classes within a component constant.

$$
\begin{aligned}
m k_{i, \text { analysis }} & =g_{j} m k_{i, \text { background }} \\
g_{j} & =\frac{\mathrm{AOD}_{\mathrm{j}, \text { analysis }}}{\mathrm{AOD}_{j, \text { background }}}
\end{aligned}
$$




\subsection{Mapping of aerosol models between observation and model spaces}

Mie theory is already used in the SYNAER retrieval to describe optical properties of aerosols. Therefore, the $\mathbf{H}$ operator also applies Mie theory to transform mass concentrations of the EURAD model aerosol classes into aerosol optical depth. Both size distribution and complex refractive index $m$ have to be defined for each EURAD aerosol class as a prerequisite for the derivation of extinction coefficients $\beta_{\text {ext }}$ in each model grid box. AOD is finally derived as the vertical integral of $\beta_{\text {ext }}$, assuming a maximum elevation of the aerosol layer up to $6 \mathrm{~km}$ as stratospheric aerosols are not treated in this study.

EURAD aerosol classes as described in Sect. 2 have to be mapped on SYNAER components. For the inorganic aerosol classes it is known how sulphuric acid, ammonium sulphate, ammonium nitrate and nitric acid with a known refractive index are created in an aqueous solution (Binkowski, 1999). Further, there are also measurements of the refractive index of elemental carbon available (Schnaiter et al., 2003).

Far more complicated is the attribution of refractive indices to those classes which consist of many and even partly unknown chemical species. This applies to the primary organic carbon particles, the anthropogenic primary particles class, and secondary organic species resulting from aromatics, alkanes, alkenes, $\alpha$-pinene and d-limonene as precursor gas phase substances, where a mass production rate per precursor mass is used in EURAD (Schell et al., 2001). Therefore, a literature study has been performed to identify dominating chemical substances observed in in-situ measurement campaigns and to identify appropriate refractive index values from chemical parameter databases (SchroedterHomscheidt, 2009).

A sensitivity study based on explicit Mie calculations in Schroedter-Homscheidt (2009) shows that the real part of the refractive index needs to be known with an accuracy of 0.1 or better to achieve an AOD uncertainty below 0.1, which is a reasonable threshold accuracy of satellite-based AOD measurements. Based on the same study, the imaginary part should be known with an accuracy of 0.03 .

Primary organic matter consist mainly of alkanes, alkanals, alkanols, fatty acids, fatty alcohols and dicarboxylic acids (Alves et al., 2001; Hahn et al., 1980; Kavaouras et al., 1999; Kendall et al., 2001; Kubatova et al., 2000; Limbeck et al., 1999; Pio et al., 2001; Saxena et al., 1995; Yassaa et al., 2001) which are typically water insoluble due to their long carbon chains. Reaction products of aromatics are typically dicarboxylic acids or substances built by several benzene rings (e.g. Hahn et al., 1980; Kawamura et al., 1999; Koch et al., 2000; Seinfeld and Pandis, 1998; Warscheid and Hoffmann, 2001). These are found to be water insoluble as well. Reaction products of alkanes are dominated by water soluble dicarboxylic acids with short carbon chains (e.g. Kawamura et al., 1999; Kerminen et al., 2000; Krivacsy et al., 2001; Pio et al., 2001; Röhrl et al., 2001; Saxena et al., 1995; Tsapakis et al., 2002; Wang et al., 2002; Yu, 2000). Reaction products of alkenes are typically aldehydes and water soluble organic acids (e.g. Forstner et al., 1997; Lang et al., 2002; Tsapakis et al., 2002), which have also been found as reaction products from $\alpha$-pinene (e.g. Kavouras et al., 1998; Pio et al., 2001; Warscheid and Hoffmann, 2001) and limonene (Koch et al., 2000). Overall, it is found that aromatic substances typically have a real part of the refractive index between 1.5 and 1.6 with an average value of 1.55 , while organic substances with linear carbon chains show values between 1.37 and 1.48, with an average value of 1.43 (Schroedter-Homscheidt, 2009). Organic species are generally identified as non-absorbing. The EURAD classes "primary fine aerosol" and "anthropogenic coarse aerosol" are not further described and mapped to the SYNAER insoluble component based on the OPAC description.

Overall, Table 2 gives an overview on the mapping of EURAD aerosol classes on SYNAER components together with the refractive index values chosen. This mapping is based on the description of aerosol species as given in the OPAC database (Hess et al., 1998), the description as given in MADE and SORGAM (Ackermann, 1995; Schell, 2001), measurements of water solubility, chemical composition, and the description of size distributions as given both in EURAD and SYNAER, and finally, the refractive index identified for all classes based on a literature overview.

The EURAD aerosol model assumes an internal mixture within each mode. Therefore, the refractive index for a EURAD particle is calculated as a volume weighted mean of refractive indices of all classes contributing in a size mode (Ouimette and Flagan, 1982).

Both EURAD and SYNAER describe the aerosol size distribution in a modal log-normal structure. EURAD size distributions in the nucleation, accumulation and coarse mode are defined with initial mean diameters of $0.01,0.07$ and $1 \mu \mathrm{m}$, respectively. The mean diameter $D_{m}$ is changing during the model run, e.g. due to coagulation or sedimentation, while the distribution width $\sigma_{m}$ is kept constant at 1.7, 2.0 and $2.2 \mu \mathrm{m}$, respectively. On the other hand, SYNAER follows the OPAC aerosol models with static size distributions for each component (see Table 1). The size distribution is only implicitly retrieved through the aerosol mixture chosen in the SYNAER procedure. Therefore, changes in the model state's size distributions by the SYNAER assimilation are not an objective of the method proposed as it would go beyond the SYNAER limitations.

Model state and observations generally do have different size distributions which affect the aerosol optical depth calculated from the model state. Sensitivity analysis shows that the extinction coefficient at $550 \mathrm{~nm}$ can vary between 0.25 and $1.5 \mathrm{~km}^{-1}$ for e.g. water insoluble aerosols, if the size distribution diameter is varied between 0.1 and $1 \mu \mathrm{m}$ while the number of particles and aerosol mass are kept constant. 
On the one hand, this calls for the use of a SYNAER equivalent size distribution in the Mie parameterisation, which is calculated from the EURAD size distribution assuming a constant aerosol mass. Therefore, the 3rd moments of both log-normal size distributions

$$
M_{l}=N D_{m}^{l} \exp \left(\frac{l^{2}}{2} \ln ^{2} \sigma_{m}\right) \quad \text { for } \quad l=3
$$

are set equal and the equation is solved for the particle number $N_{\text {SYNAER }}$ of "equivalent SYNAER particles".

$$
N_{\text {SYNAER }}=\frac{N_{\text {EURAD }} D_{m, \text { EURAD }}^{3} \exp \left[\frac{9}{2}\left(\ln \sigma_{m, \text { EURAD }}\right)^{2}\right]}{D_{m, \text { SYNAER }}^{3} \exp \left[\frac{9}{2}\left(\ln \sigma_{m, \text { SYNAER }}\right)^{2}\right]}
$$

On the other hand, this sensitivity shows that observations with a large disagreement in their size distribution vs. the current model state should be excluded in a pre-processing step as those might introduce the risk of violating the linear approximation assumed in Eq. (1). This should be assessed again in future once large particles in the mineral and/or sea salt components will be assimilated into a EURAD system.

For this case study it has been found that $35 \%$ of AOD based on the EURAD size distribution show less than a difference of 0.01 compared to the AOD based on the SYNAER equivalent size distribution; $82 \%$ are within a 0.05 difference and $96 \%$ show a difference below 0.1. Compared to today's root mean square error (RMSE) target accuracies of 0.1 for satellite observations, this effect has been neglected in this study. It should be noted, that this effect cannot be neglected in general, but should be assessed on a case by case basis in a pre-processing and quality control step in a later operational assimilation scheme.

\subsection{Covariance matrices for model background and observations}

A definition of both the background and observation error covariance matrix is needed to evaluate the use of the observation operator developed in this study and described below. In both cases it is derived by comparing to ground-based AERONET measurements.

\subsubsection{Observation error quantification}

A quality control procedure for observations is requested to eliminate outliers. As for all least square based data assimilation algorithms, Eq. (2) implies the assumption that errors both in observations and model background follow a Gaussian distribution assuming a negligible probability for large outliers. Frequent outliers in the observation dataset would violate this assumption.

A validation of SYNAER-ENVISAT (version 1.8) by AERONET ground measurements (version 2, level 1.5) for 334 overpasses over Europe, Africa and South America for the study period was conducted. The AERONET coincidences show a mean AOD value of 0.24. Without any further quality control of SYNAER observations, an AOD bias of -0.06 representing an underestimation compared to AERONET and a RMSE of 0.17 is found for Europe. For all regions (Europe, Africa and Southern America) the bias is found to be -0.08 with a RMSE of 0.27 . This data set is further analysed to develop an automatic quality control.

The automatic quality control relies on the following considerations:

1. Large solar zenith angles above $75^{\circ}$ are excluded due to a low signal-to-noise ratio.

2. SYNAER is only applied to SCIAMACHY pixels with cloud coverage below 50\%. Below this threshold a dependence of deviations between SYNAER and AERONET on cloud cover cannot be found.

3. High values of ground albedo also reduce the signal-tonoise ratio.

4. The SYNAER retrieval includes 40 different aerosol mixtures, which cannot fully be separated from each other according to an information content analysis (Holzer-Popp et al., 2008). SYNAER defines the ambiguity error $E_{m}$ as

$$
E_{m}=\sqrt{\sum_{j=1}^{p} \frac{\left(\mathrm{AOD}_{j}-\mathrm{AOD}_{k}\right)^{2}}{p-1}}
$$

for all $p(p>1)$ undistinguishable aerosol mixtures. Undistinguishable mixtures are defined as those, where the least square fit of the $\mathrm{j}$-th aerosol mixture are closer to the least square fit of the retrieved aerosol mixture $k$ than these are different from the satellite measured reflectances at all $l$ wavelengths $(l=10)$

$$
\sum_{l=1}^{10}\left(R_{\lambda_{l}, j}-R_{\lambda_{l}, k}\right)^{2}<\sum_{l=1}^{10}\left(R_{\lambda_{l}, \text { meas }}-R_{\lambda_{l}, k}\right)^{2}
$$

The fit error $E_{f}$ on the basis of all reflectances $R$ at the 10 wavelengths $\lambda_{l}$ serves to control retrieval fit quality and is defined in SYNAER as

$$
E_{f}=\sqrt{\sum_{l=1}^{10}\left(R_{\lambda_{l}, \text { meas }}-R_{\lambda_{l}, k}\right)^{2}}
$$

Comparisons against AERONET observations show that large SYNAER overestimations occur if the ambiguity error $E_{m}>0.1$ is combined with a land surface albedo above $15 \%$. Additionally, large underestimations are found for $E_{m}>0.05$ for water pixels with a surface albedo above $5 \%$. Finally, pixels with $E_{f}>0.025$ are also excluded to eliminate outliers. 
Using these quality control criteria, the bias for all regions (Europe, Africa and Southern America) remains the same at -0.08 , but the standard deviation $\sigma_{\text {SYNAER-AERONET }}$ is reduced from 0.26 to 0.1 . The RMSE decreases from 0.27 to 0.12 and the correlation coefficient increases significantly from 0.3 to 0.73 . The number of coincidences in the validation study is reduced by $24 \%$ to 105 pixels.

Due to the limited number of available validation pixels, a regional variability in $R$ is not assumed in this study. Using this quality control procedure as pre-processing and assuming a diagonal structure representing uncorrelated observations, the observation error covariance matrix $\mathbf{R}$ is set to a constant diagonal element value of $(0.12)^{2}$ taking the RMSE as a standard deviation.

Compared to the 0.1 target accuracy of nowadays satellite retrieval scheme the bias is rather small and therefore neglected here even if it is close to the standard deviation found. It should be noted that a recent validation of SYNAER version 2.2 observations has shown a reduced bias of -0.01 (instead of -0.08 for the SYNAER version 1.8 used in this study) and an improved standard deviation of 0.08 (HolzerPopp et al., 2008). Additionally, it is assumed that the error in AERONET is negligible compared to the bias found for SYNAER.

\subsubsection{Background error quantification}

A validation of the model state at 10:00 UTC vs. AERONET ground measurements (version 2, level 2) is conducted for the study period, revealing a total of 2268 coincidences with AERONET measurements available between 9:00 and 11:00 UTC with an observation mean value of 0.22 . In case of several AERONET measurements within this time period, the closest measurement has been chosen. It has to be noted, that AERONET provides ground measurements only in cloud-free situations. Overall, an underestimation of -0.15 and a standard deviation $\sigma_{\text {EURAD-AERONET }}=0.17$ is found for the EURAD model. Especially AOD above 0.1 are underestimated. This agrees with other studies, finding $\mathrm{PM}_{10}$ and $\mathrm{PM}_{2.5}$ underestimated for Europe in air quality models for example Sartelet et al. (2007) for the POLYPHEMUS model or Vautard et al. (2007) for the models CHIMERE, EMEP, LOTOS (Long-Term Ozone Simulation model), REM-CALGRID (Regional Eulerian ModelCalifornia Grid), OFIS (Ozone Fine Structure Model) and CAMx (Comprehensive Air Quality Model). The EURAD underestimation occurs at all European AERONET stations and reaches its largest values with a bias of up to -0.25 in Italy and Turkey.

A separate monthly analysis reveals strong underestimation in July and August by -0.17 and -0.21 , respectively. In contrast, the bias is reduced to -0.1 in September and October and to -0.08 in November 2003. The standard deviation $\sigma_{\text {EURAD-AERONET }}$ shows no clear seasonality with $0.17,0.17,0.13,0.21$ and 0.15 for the months July to Novem- ber, respectively. The large underestimation in July and August is probably caused by dust outbreak events from Sahara (Breitkreuz et al., 2009), which have not been modelled explicitly in the EURAD version used. Also, the extraordinary hot summer in 2003 may have caused less vegetation cover and increased erosion on agricultural land which is not taken into account in the static aerosol emission databases.

The background validation indicates a remarkable bias which might be judged as not suitable for data assimilation purposes. However, in the meanwhile a dust model has been included in EURAD and it is expected that the overall bias will be reduced in a foreseen operational assimilation scheme. Additionally, it has to be taken into account that the EURAD model provides a physically and chemically consistent distribution between particle types which is of value in itself. A sustainable bias correction scheme could not be developed in this study as the bias is highly variable in space and time and not known yet due to the restricted data availability of only 5 months. Therefore, it was decided to apply the data assimilation as a correction mechanism without claiming a BLUE analysis. On the other hand, this study deals mainly with the observation operator and a first assessment of the value of the assimilation of aerosol component resolving observations into a CTM by assessing analysis fields vs. ground measurements. Therefore, an assimilation experiment is needed as part of the study and for this purpose, an increase of the diagonal element in the initial background error covariance matrix above the squared standard deviation found in the validation was chosen as a first step and its value is set to $(0.3)^{2}$. This reduces the weight of the model state in the assimilation, reflecting implicitly the bias problem found for this study data set.

\section{Validation of resulting analysis fields}

In the following sections, reports on validation studies either of AOD or particle mass concentrations in the analysis are given. Due to the low repetition frequency of ENVISAT (12 days with cloud-free conditions and less due to clouds) and the restricted number of available observations an overall impact of the assimilation can hardly be seen. Assessing spatial impact distributions based on ENVISAT observations would result merely in a mapping of satellite tracks rather than resulting in physically meaningful spatial patterns. It has to be noted that a future METOP assimilation will rely on a significantly larger number of observations.

Therefore, further validation is performed only in the vicinity of existing SYNAER observations which might cause any positive or negative impact. Only grid boxes having a non-zero analysis increment are taken into account. Non-zero analysis increment grid boxes occur due to a finite number of diffusion time steps. This criterion excludes situations where background and observations agree fully, but this occurs only in $0.04 \%$ of all cases. This is also justified 
as these cases would not contribute to any impact on the assimilation result.

\subsection{Total aerosol optical depth}

The comparison of analysed AOD fields vs. AERONET ground measurements reveals 189 coincidences for the whole study period in Europe with a non-zero analysis increment. The validation shows a slight reduction of bias between the background and analysis fields from -0.14 to -0.12 while

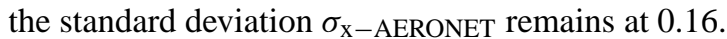

Requiring an analysis increment larger than 0.05 reduces the number of coincidences to 53 with a mean observation AOD of 0.24 , but shows also a significant improvement of the overall bias from -0.15 to 0.07 and a reduction in RMSE from 0.25 to 0.2 (Fig. 1). The overall standard deviation reduces only slightly from 0.2 to 0.19 . The RMSE is significantly reduced at IMC-Oristano (0.5 to 0.22), El Arenosillo (0.23 to 0.15$)$, Oostende (0.3 to 0.23$)$, Dunkerque (0.19 to $0.13)$ and Forth Crete (0.11 to 0.05). Also, Lampedusa, Evora and Venice are slightly improved. Only at Toulouse and ISDGM_CNR the RMSE is slightly increased by 0.03 . IMC-Oristano, El Arenosillo, Forth Crete, Lampedusa and Venice have been shown to be affected by dust outbreaks in this period (Breitkreuz et al., 2009). This motivates the validation of specific dust outbreak situations as given in Sect. 4.5.

\subsection{Soot mass concentrations}

There is no Europe-wide ground measurement network for mass concentrations of elementary and organic carbon available. National standards cannot be easily compared to each other (EMEP, 2007) or the density of ground stations is small. However, in the United Kingdom the Black Smoke and Sulphur Dioxide Network provides a rather dense network with 137 stations using a single measurement standard.

The sum of elementary and organic carbon as modelled in EURAD for 10 UTC is compared with the daily mean black carbon (BC) ground measurements. The difference of daily mean measurements and instantaneous model results is neglected. This is justified as the chosen ground stations are located in background conditions without a systematic intraday variation as typically found in the vicinity of emission sources. Nevertheless, a possible additional gradient due to large scale meteorological conditions is neglected and contributes to the scatter observed.

Overall, 231 coincidences with an analysis increment above 0.001 in soot AOD can be found in the study period. The assimilation causes a bias reduction from -3.66 to $-1.38 \mu \mathrm{g} / \mathrm{m}^{3}$, but increases the standard deviation from 3.22 to $5.37 \mu \mathrm{g} / \mathrm{m}^{3}$ (Fig. 2). Single coincidences show overestimations up to $22 \mu \mathrm{g} / \mathrm{m}^{3}$ after the assimilation.

All outliers with differences $\mathrm{BC}_{\mathrm{X}_{-} \mathrm{a}}-\mathrm{BC}_{\text {ground }}>5 \mu \mathrm{g} / \mathrm{m}^{3}$ are evaluated separately using $300 \mathrm{~m}$ spatially resolving MODIS colour composites. All these differences occur at
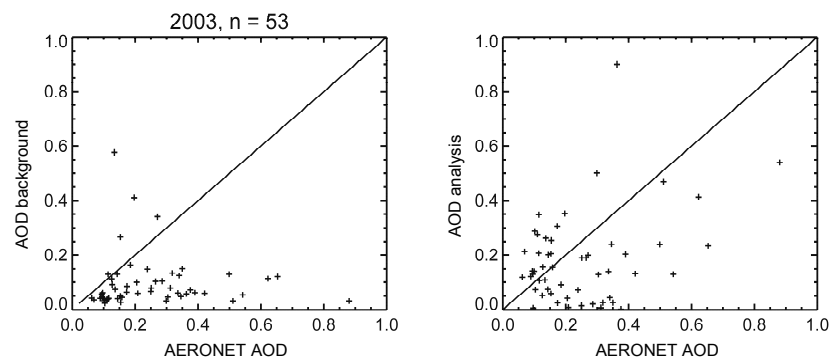

Fig. 1. Comparison of background field AOD vs. AERONET ground measurements (left) and of analysed field AOD vs. AERONET (right) for 53 coincidences with a minimum analysis increment of 0.05 during the study period July-November 2003 in Europe.

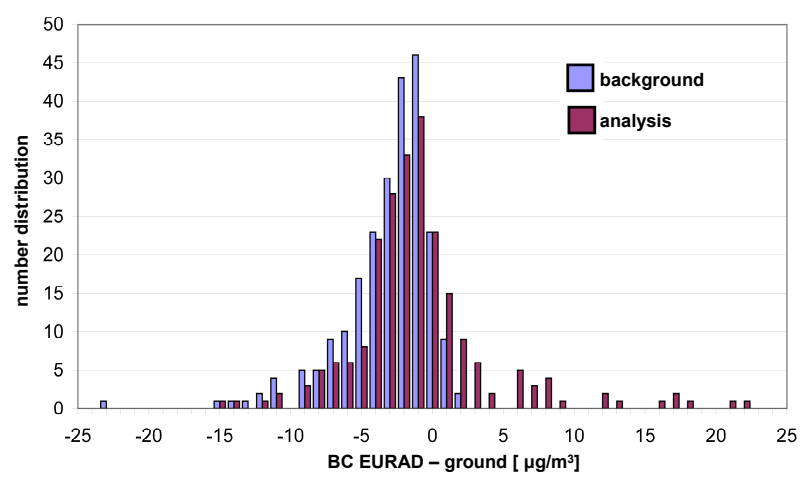

Fig. 2. Number distribution of differences $B C_{X_{-} b-\text { ground }}$ and $\mathrm{BC}_{\mathrm{X} \_\mathrm{a}-\text { ground }}$ for 231 coincidences in the United Kingdom within July to November 2003 for both the background (blue) and the analysis (purple) field.

the edge of cloud fields or in areas with small scale clouds. Therefore, it is assumed that errors in cloud detection and clearing in the satellite observations cause an overestimation in AOD and therefore in the analysis field. Unfortunately, these cases show no remarkable patterns either in cloud cover, ambiguity error Eq. (11) or fit error Eq. (13), which would allow an automatic exclusion.

After manual exclusion of these outliers, the overall bias in the $\mathrm{BC}$ mass concentration is reduced from -3.63 to $-2.73 \mu \mathrm{g} / \mathrm{m}^{3}$ together with a reduction in standard deviation from 3.25 to $3.08 \mu \mathrm{g} / \mathrm{m}^{3}$ and a RMSE reduction from 4.87 to $4.12 \mu \mathrm{g} / \mathrm{m}^{3}$. Ground measurements show a mean value of $4.98 \mu \mathrm{g} / \mathrm{m}^{3}$ for these cases. It has to be noted that this improvement is in the range of the uncertainty of the ground measurement network which is given as $30 \%$. On the other hand, a significance test rejects the zero hypothesis, that analysis and background field are originating from the same basic population with a significance level below $1 \%$. Therefore, a positive impact of the assimilation of SYNAER observations on the SOOT component can be stated, together with a strong emphasis on the need of strict cloud clearing in SYNAER observations. 
The scatter remains rather large compared to the ground measurement uncertainty. On the other hand, a case study on 15 September 2003 for 3 carbon measuring ground stations in the bay of Gibraltar (Algeciras, La Linea, and Los Barrios) within the COST 633 campaign data base of the European Commission shows the typical variability within a EURAD grid box: The SYNAER assimilation raises the value for the grid box from $0.4 \mu \mathrm{g} / \mathrm{m}^{3}$ in the background to $4.13 \mu \mathrm{g} / \mathrm{m}^{3}$ in the analysis which is a positive impact if compared to the $3.1 \mu \mathrm{g} / \mathrm{m}^{3}$ mean of the 3 stations. On the other hand, the comparison with each single measurement results in a mismatch from $-20 \%$ underestimation up to $120 \%$ overestimation in the analysis field illustrating the intra-grid box variability and explaining the scatter in validation studies using grid boxes or satellite pixels vs. in situ measurements.

\subsection{Water soluble mass concentrations}

A further study focus is placed on the validation of mass concentrations of the water soluble aerosol component vs. EMEP mass concentration measurements of $\mathrm{SO}_{4}$, $\mathrm{NH}_{4}$ und $\mathrm{NO}_{3}$. EURAD mass concentrations are converted to $\mu \mathrm{g} \mathrm{S} / \mathrm{m}^{3}$ and $\mu \mathrm{g} \mathrm{N} / \mathrm{m}^{3}$ as provided by the EMEP network based on the molar masses of EURAD aerosol species. Finally, the sum of sulphur and nitrogen is compared as the assimilation is performed for the integrated WASO aerosol component and does not distinguish further between water soluble aerosol species. EMEP stations provide also daily mean values typical for background conditions, which are compared with 10:00 UTC EURAD background and analysis fields. The implications of this assumption have been already discussed in Sect. 4.2.

Overall, 81 coincidences with an analysis increment above 0.01 in AOD at 16 stations in Hungary, Italy, Lithuania, the Netherlands, Norway, Poland, Russia and Turkey can be found for the period July to November 2003. This bias is reduced from 2.11 to $1.38 \mu \mathrm{g}(\mathrm{S}+\mathrm{N}) / \mathrm{m}^{3}$, the standard deviation is decreased from 3.7 to $3.43(\mathrm{~S}+\mathrm{N}) / \mathrm{m}^{3}$ and the RMSE from 4.27 to $3.7(\mathrm{~S}+\mathrm{N}) / \mathrm{m}^{3}$ (Fig. 3) showing also a positive impact of the assimilation for the water soluble component. It has to be noted that this result was derived for ground stations representative for background conditions with a mean value of $2.14 \mu \mathrm{g}(\mathrm{S}+\mathrm{N}) / \mathrm{m}^{3}$ and a maximum value of $8.67 \mu \mathrm{g}(\mathrm{S}+\mathrm{N}) / \mathrm{m}^{3}$. A validation for nonbackground conditions cannot be provided on that basis.

\subsection{Soot aerosol optical depth}

In August 2003 an intensive wild fire and biomass burning period affected Portugal and Southern Spain. Observations show high soot-induced AOD levels, which are not modelled in the EURAD background field. Figure 4 shows differences of soot observations vs. the model background ("observations minus forecast", OmF) of up to 0.15 (left panel) on the Iberian Peninsula due to these wild fires and additional pos-

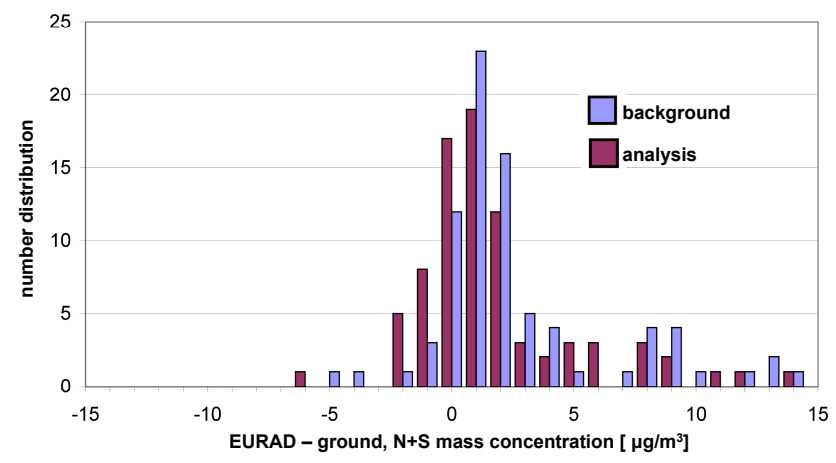

Fig. 3. Number distribution of differences in nitrogen and sulphur mass concentrations for 81 coincidences with EMEP stations in 8 European countries within July to November 2003 for both the background (blue) and the analysis (purple) field.

itive $\mathrm{OmF}$ values in the Mediterranean area. Also, the water soluble component shows OmF up to 0.4 over the Iberian Peninsula due to the incomplete burning of wild fires. The assimilation includes these observations successfully, showing differences between the SOOT observations and the analysis field (OmA) close to zero.

The validation of analysed total AOD by AERONET ground measurements for all European stations in $\mathrm{Au}-$ gust 2003 shows an improvement by assimilation. If all coincidences with an analysis increment larger than 0.05 in AOD are taken into account, the bias because of underestimation is reduced from -0.29 to -0.13 , while RMSE is reduced from 0.35 to 0.26 , and the standard deviation $\sigma_{\text {ANALYSIS-AERONET }}$ remains nearly constant ( 0.21 to 0.22 ). The AERONET mean AOD value for these cases is 0.36 . Unfortunately, there are no soot mass concentration ground measurements in the vicinity of ENVISAT overpasses available in August 2003 for any independent quantitative evaluation.

\subsection{Mineral dust aerosol optical depth}

Case studies of dust outbreaks are selected based on MODIS colour composites (http://modis-atmos.gsfc.nasa. gov/IMAGES/index.html). A number of 29 days with an ENVISAT overpass in a region with a dust outbreak event is selected visually. Overall, 10 coincidences between AERONET ground measurements and corresponding EURAD simulation with an analysis increment above 0.05 in AOD can be found. These cases include the stations El Arenosillo (2 days), Etna, Forth Crete, Lampedusa (3 days), Lecce, and IMC-Oristano.

Observed and simulated total AOD values are compared in these cases at locations, where total AOD is dominated by dust events. Therefore, we assume that the results characterize the assimilation impact for dust cases. AOD bias is reduced from -0.26 to -0.07 and RMSE is decreased from 


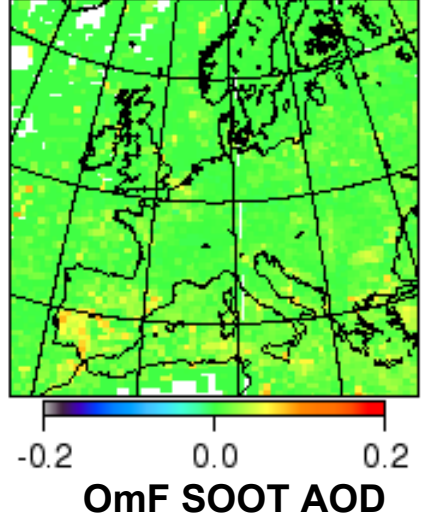

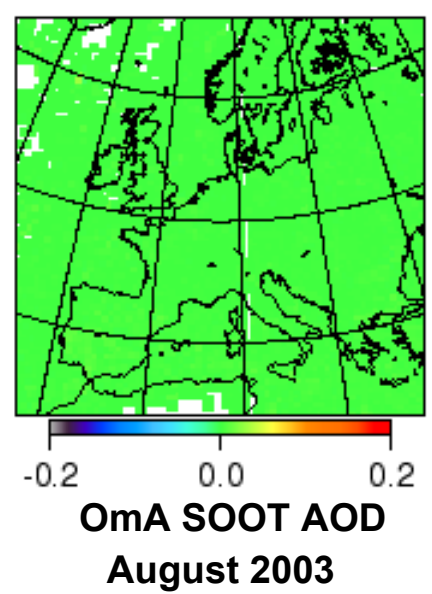

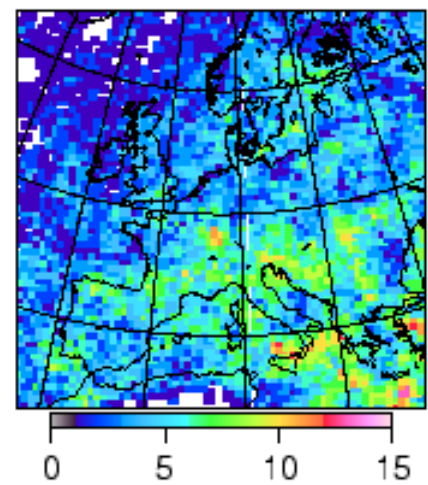

no. of observations

Fig. 4. Map of SOOT component differences for observations minus forecast (left), observations minus analysis (middle) and number of observations used for each EURAD grid box in August 2003 (right). The wild fire induced signal in the observations is visible over the Iberian Peninsula and North of Algeria (yellow and orange color) and disappears in the analysis field (green colors indicating OmF and OmA around zero).

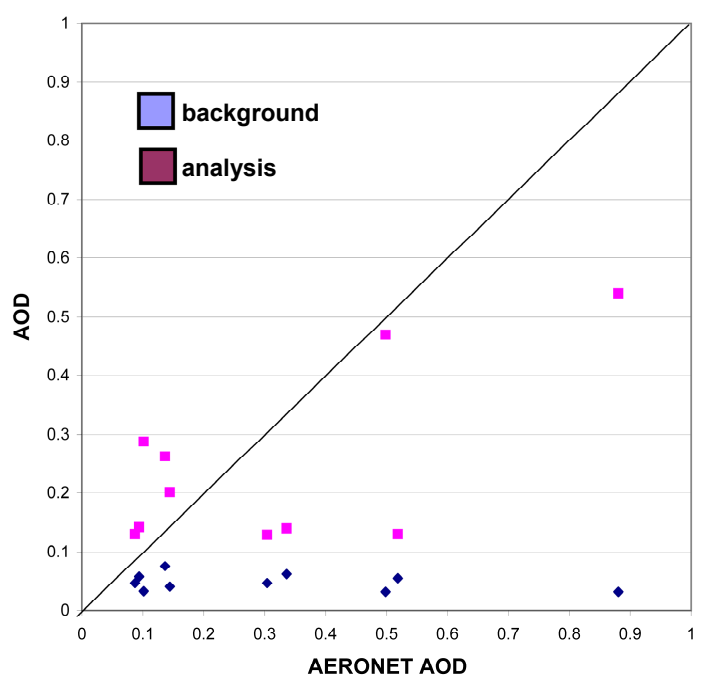

Fig. 5. Background (blue) and analysis (purple) field AOD vs. AERONET AOD measurements for 10 dust outbreak cases in the July to November 2003 period.

0.38 to 0.21 (Fig. 5) while the AERONET AOD shows a mean value of 0.38 in these cases.

It has to be noted that this positive impact is only attributed to the increased value of the WASO component observation in dust cases as there is no explicit assimilation of the SYNAER mineral component observation performed in this study. This is due to the missing dust module in the EURAD version used. But as SYNAER includes a $25 \%$ WASO background in all aerosol mixtures, a large signal in the mineral component is always accompanied by a larger signal in WASO which shows its positive impact in terms of total AOD.

\section{Discussion and conclusions}

An observation operator for a variational 2-D-Var assimilation approach using satellite-based SYNAER aerosol component observations and the EURAD chemical transport model has been developed. The study is motivated by an expected positive impact of data assimilation of satellite observations for dynamic aerosol sources like dust outbreaks, fires, vegetation and changing human activities.

Up to now most studies dealt with $\mathrm{PM}_{10}$ or total aerosol optical depth, while the component-wise and separate assimilation of aerosol observations like the SYNAER water soluble, insoluble, soot, mineral or sea salt components is a novel approach. MODIS based fine and coarse mode observations might be another option in the future, but are still under scientific discussion (Levy et al., 2010).

The observation operator couples the chemical aerosol description in the EURAD model with the optical aerosol description used as a basis in SYNAER satellite observations. Therefore, an update of refractive indices, the handling of different size distributions in observations and background fields, and a fast parameterisation of Mie theory are combined. A literature review results in an organic aerosol species database describing primary organic matter mainly as consisting of typically water insoluble alkanes, alkanals, alkanols, fatty acids, fatty alcohols and dicarboxylic acids. Reaction products of aromatics are typically water insoluble dicarboxylic acids, while reaction products of alkanes are dominated by water soluble dicarboxylic acids with short carbon chains. Reaction products of alkenes are typically aldehydes and water soluble organic acids, which have also been identified as reaction products from $\alpha$-pinene and limonene. Overall, it is found that aromatic substances typically have a real part of the refractive index between 1.5 
and 1.6 with an average value of 1.55 , while organic substances with linear carbon chains show values between 1.37 and 1.48 , with an average value of 1.43 . All organic species in this database can be treated as non-absorbing.

A best linear and unbiased estimator (BLUE) assimilation approach is chosen, which requests an automatic quality control for SYNAER observations to exclude outliers. The approach presented is based only on implicit parameters available from the satellite retrieval itself.

For all validation results a scale effect should be taken into account. Holzer-Popp et al. (2008) showed that a noise of 0.05 in AOD can be expected if a SYNAER pixel or an EURAD grid box is compared against an AERONET point measurement.

A validation of AOD background EURAD fields and SYNAER observations vs. AERONET ground measurements is performed to define background and observation error matrices as a prerequisite for the derivation of analysis fields by a 2-D-Var procedure. This validation shows that both the background and the observations are affected by significant biases which are a risk in terms of the validity of the BLUE approach. It is known that currently most chemical transport models show a similar bias which has not been further defined yet and is therefore not removable by any sophisticated bias correction scheme. On the other hand recent validation of SYNAER version 2.2 observations has shown a reduced bias of -0.01 (instead of -0.08 for the SYNAER version used in this study) and an improved standard deviation of 0.08 which is promising for the future (Holzer-Popp et al., 2008). Therefore, it is decided to use SYNAER observations in an assimilation approach to correct the background state, but without claiming a BLUE analysis. The improvement gained through this approach is shown by an assessment of the analysis. Additionally, the EURAD model is currently being enhanced by including additional processes like secondary organics and wind-blown dust into the aerosol mechanism. For a future operational application of the study results, a background bias correction scheme needs to be developed to ensure the BLUE. It could either be based on an assessment of a long-term dataset or on a continuous bias monitoring scheme as applied e.g. in Dee et al. (1998). It has to be noted that the settings of the background error covariance matrix in this study are preliminary allowing an assimilation experiment within the study and therefore, the assessment of the value of aerosol component distinguishing satellite observations in an assimilation scheme.

Analysis fields are validated for total AOD by AERONET ground measurements both in all situations and in dust outbreak cases separately. To show the positive impact of assimilated SYNAER observations, mass concentration analysis fields are compared with the water soluble aerosol component as measured by the EMEP network and black carbon as measured by the UK Black Smoke and Sulphur Dioxide network. Due to the sparse data availability of ENVISAT all comparisons are made only in the vicinity of observations, which is classified by an analysis increment above zero.

A positive impact of SYNAER observations on modelled AOD can be observed for nearly all European stations, with special effect by Mediterranean stations. Additionally, a positive impact of the component-wise available SYNAER observations on modelled mass concentrations of water soluble and carbonaceous aerosol components is shown, together with a positive impact on AOD in dust outbreak cases. For a wild fire episode in Portugal a positive OmF can be found indicating a positive impact also for fire events which is confirmed through AOD validation by AERONET.

It has been shown that the systematic error in all aerosol components can be significantly reduced by the assimilation, while the scatter remains nearly unchanged. The latter finding is not surprising as it represents the error in time and space caused by the comparison of $56 \mathrm{~km}$ sized grid boxes vs. point ground measurements. A case study of 3 stations within a grid box in Spain shows that the differences between analysis field in the grid box and the individual station can range from $-20 \%$ underestimation to $+120 \%$ overestimation.

Overall, the foundation for the operational use of METOP SYNAER observations with a largely extended temporal and spatial coverage has been laid within this study. Based on longer time periods and more observations as available from METOP, an extended error covariance matrix definition is ongoing (Holzer-Popp et al., 2008; Martynenko et al., 2009) as a further step towards an operational sequential assimilation of SYNAER component AOD observations into the EURAD model. Additionally, an assessment of spatial patterns of analysis increments based on the improved METOP coverage is foreseen.

The estimation of SYNAER equivalent size distributions as given in Eq. (10) for the EURAD background becomes unreliable if the mode diameter between the two distributions differs largely. In case of a future direct assimilation of mineral dust observations this has to be taken into account and such cases should be excluded in a pre-processing step.

Acknowledgements. Our thanks for the provision of ground measurements go to the UK Black Smoke and Sulphur Dioxide Network; Jean Philippe Putaud and Xavier Querol for data from the Cost633 data base; Ana Maria Silva, Anatoli Chaikovsky, Andrew Clive Banks, Arnon Karnieli, Bertil Hakansson, Brent Holben, Christoph Kleefeld, Christophe Francois, Didier Tanré, Gian Paolo Gobbi, Gilbert Sappe, Giuseppe Zibordi, Hammad Ben-Chekroun, Jean-Francois Leon, Jens Boesenberg, Kevin Ruddick, Luigi Alberotanza, Maria Rita Perrone, Natalia Chubarova, Olavi Kärner, Paulo Artaxo, Peter Koepke, Philippe Goloub, Rachel T. Pinker, Roland Doerffer, Serge Despiau, Sergio Pugnaghi, Spyros Rapsomanikis, and Victoria E. Cachorro Revilla for their AERONET measurements; and last but not least to Alexey Ryaboshapko, Arien Stolk, Barbara Obminska, Cinzia Perrino, Iraida Luylko, Laszlo Haszpra, Lütfü Kylyclar, 
and Wenche Aas being responsible for EMEP stations. ENVISAT satellite raw data have been provided by the European Space Agency within the AO project SENECA. We also thank the anonymous reviewers for their helpful comments.

Edited by: W. Lahoz

\section{References}

Ackermann, I. J., Hass, H., Memmesheimer, M., Ziegenbein, C., and Ebel, A.: The parameterization of the sulfate-nitrateammonia aerosol system in the long-range transport model EURAD, Meteorolog. Atmos. Phys., 57, 101-114, 1995.

Ackermann, I. J., Hass, H., Memmesheimer, M., Ebel, A., Binkowski, F. S., and Shankar, U.: MADE: Modal Aerosol Dynamics Model for Europe; development and first applications, Atmos. Environ., 32(17), 2981-2999, 1998.

Alves, C., Pio, C., and Duarte, A.: The organic composition of air particulate matter from rural and urban portuguese areas, Phys. Chem. Earth Pt. B, 24(6), 705-709, 1999.

Anderson, T. L., Charlson, R. J., Winker, D. M., Ogren, J. A., and Holmen, K.: Mesoscale Variations of Tropospheric Aerosols, J. Atmos. Sci., 60, 119-136, 2003.

Berdowski, J. J. M, Mulder, W., Veldt, C., Visschedijk, A. J. H., and Zandveld, P. Y. J.: Particulate matter emissions $\left(\mathrm{PM}_{10}-\mathrm{PM}_{2.5}\right.$ - $\left.\mathrm{PM}_{0.1}\right)$ in Europe in 1990 and 1993, TNO-report TNO-MEPR96/472, 1996.

Binkowski, F. S.: Aerosols in Models-3 CMAQ, Kapitel 10 in: Science algorithms of the EPA Models-3 Community Multiscale Air Quality (CMAQ) Modelling System, edited by: Byun, D. W. and Ching, J. K. S., United Stated Environmental Protection Agency, report EPA/600/R-99/030, March, available at: http://www.epa.gov/asmdnerl/models3/doc/science/science. html, 1999.

Bouttier, F. and Courtier, P.: Data assimilation concepts and methods, Meteorological Training Course Lecture Series, European Centre for Middle-Range Weather Forecasting (ECMWF), 1999.

Breitkreuz, H., Schroedter-Homscheidt, M., Holzer-Popp, T., and Dech, S.: Short-Range Direct and Diffuse Irradiance Forecasts for Solar Energy Applications Based on Aerosol Chemical Transport and Numerical Weather Modeling, J. Appl. Meteorol., 48, 9, 1766-1779, 2009.

Builtjes, P. J. H., Borrego, C., Carvalho, A. C., Ebel, A., Memmesheimer, M., Feichtner, H., Münzenberg, A., Schaller, E., and Zlatev, Z.: Global and Regional Atmospheric Modeling, Overview over the Subproject GLOREAM, in: Towards Cleaner Air for Europe - Science, Tools and Applications, Part 2: Overview from the Final Reports of EUROTRAC-2 Subprojects, edited by: Midgley, P. M. and Reuther, M. Markgraf Publishers, Weikersheim, 139-164, 2003.

Chin, M., Ginoux, P., Kinne, S., Holben, B. N., Duncan, B. N., Martin, R. V., Logan, J. A., Higurashi, A., and Nakajima, T.: Tropospheric aerosol optical thickness from the GOCART model and comparisons with satellite and sunphotometer measurements, J. Atmos. Sci., 59, 461-483, 2002.

Collins, W. D., Rasch, P. J., Eaton, B. E., Khattatov, B. V., and Lamarque, J. F.: Simulating aerosols using a chemical transport model with assimilation of satellite aerosol retrievals: Methodology for INDOEX, J. Geophys. Res., 106(D7), 7313-7336, 2001.
Daley, R.: Atmospheric Data Analysis, Cambridge Atmospheric and Space Science Series, Cambridge University Press, ISBN 0-521-38215-7, 1991.

Dee, D. P. and Da Silva, A. M: Data assimilation in the presence of forecast bias, Q. J. Roy. Meteor. Soc., 124, 269-295, 1998.

Dubovik, O., Holben, B., Eck, T. F., Smirnov, A., Kaufman, Y. J., King, M. D., Tanré, D., and Slutsker, I.: Variability of Absorption and Optical Properties of Key Aerosol Types Observed in Worldwide Locations, J. Atmos. Sci., 59, 590-608, 2002.

Ebel, A.: Entwicklung und Stand des EURAD-Vorhabens, in: Das EURAD-Modell: Aufbau und erste Ergebnisse, Mitteilungen aus dem Institut für Geophysik und Meteorologie der Universität zu Köln, Heft 61, 1-5, 1989.

Ebel, A., Moussiopoulus, N., Becker, K. H., Borrego, C. A., Bouscaren, R., Builtjes, P. J. H., Flossmann, A., Hansen, U., Hantel, M., Hass, H., Poppe, D., and Rosset, R.: Air quality modelling and models in EUMAC: an overview, in: Transport and Chemical Transformation of Pollutants in the Troposphere, edited by: Borrel, P. et al., vol. 7, Tropospheric Modelling and Emission Estimation, edited by: Ebel, A., Friedrich, R., and Rohde, H., 3-24, 1997a.

Ebel, A., Elbern, H., Feldmann, H., Jakobs, H. J., Kessler, C., Memmesheimer, M., Oberreuther, A., and Piekorz, G.: Air Pollution Studies within the EURAD Model System (3): EURAD European Air Pollution Dispersion Model System. Mitteilungen aus dem Institut für Geophysik und Meteorologie der Universität zu Köln, edited by: Ebel, A., Kerschgens, M., Neubauer, F. M., Speth, P., Heft Nr. 120, 1997b.

Elbern, H., Schmidt, H., and Ebel, A.: Variational data assimilation for tropospheric chemistry modeling, J. Geophys. Res., 10(D13), 15967-15985, 1997.

Elbern, H. and Schmidt, H.: Ozone episode analysis by fourdimensional variational chemistry data assimilation, J. Geophys. Res., 106(D4), 3569-3590, 2001.

Elbern, H., Strunk, A., Schmidt, H., and Talagrand, O.: Emission rate and chemical state estimation by 4-dimensional variational inversion, Atmos. Chem. Phys., 7, 3749-3769, doi:10.5194/acp7-3749-2007, 2007.

EMEP: EMEP manual for sampling and chemical analysis, NILUReport, 2001 EMEP/CCC-Report 1/95, Referenz O-7726, März 1996, 1. Revision November 2001.

EMEP: Transboundary particulate matter in Europe, Status report 4/2007, NILU-Report O-98134, August 2007.

Engelstaedter, S., Tegen, I., and Washington, R.: North African dust emissions and transport, Earth-Science Reviews, 79(1-2), 73100, 2006.

Evans, B. T. N. and Fournier, G. R.: Simple approximation to extinction efficiency valid over all size parameters, Appl. Optics, 29, 31, 4666-4670, 1990.

Forstner, H. J. L., Flagan, R. C., and Seinfeld, J. H.: Molecular speciation of secondary organic aerosol from photooxidation of the higher alkenes: 1-octene and 1-decene, Atmos. Environ., 31(13), 1953-1964, 1997.

Generoso, S., Breon, F.-M., Chevallier, F., Balkanski, Y., Schulz, M., and Bey, I.: Assimilation of POLDER aerosol optical thickness into the LMDz-INCA model: Implications for the Arctic aerosol burden, J. Geophys. Res. 112, D02311, doi:10.1029/2005JD006954, 2007.

Ghil, M.: Meteorological Data Assimilation for Oceanographers - 
Part 1: Description and Theoretical Framework, Dyn. Atmos. Oceans, 13, 171-218, 1989.

Grell, G. A., Dudhia, J., and Stauffer, D. R.: A description of the fifth-generation Penn State/NCAR mesoscale model (MM5), NCAR technical note, NCAR/TN-398+STR, 1994.

Hahn, J.: Organic Constituents of Natural Aerosols, in: Aerosols: Anthropogenic and Natural, Sources and Transport, edited by: Kneip, T. J. and Lioy, P. J., Annals of the New York Academy of Sciences, vol. 338, New York, 1980.

Hara, Y., Yumimoto, K., Uno, I., Shimizu, A., Sugimoto, N., Liu, Z., and Winker, D. M.: Asian dust outflow in the PBL and free atmosphere retrieved by NASA CALIPSO and an assimilated dust transport model, Atmos. Chem. Phys., 9, 1227-1239, doi:10.5194/acp-9-1227-2009, 2009.

Hess, M., Köpke, P., and Schult, I.: Optical Properties of Aerosols and Clouds: The Software package OPAC, B. Am. Meteor. Soc., 79, 831-844, 1998.

Holben, B. N., Eck, T. F., Slutsker, I., Tanré, D., Buis, J. P., Setzer, A., Vermote, E., Reagan, J. A., Kaufmann, Y. J., Nakajima, T., Lavenu, F., Jankowiak, I., and Smirnov, A.: AERONET: A federated instrument network and data archive for aerosol characterization, Remote Sens. Environ., 66, 1-16, 1998.

Holzer-Popp, T., Schroedter, M., and Gesell, G.: Retrieval of aerosol optical depth and type in the boundary layer over land and ocean from simultaneous GOME spectrometer and ATSR2 radiometer measurements -1 . Model description, J. Geophys. Res., 107(D21), 4578-4594, 2002a.

Holzer-Popp, T., Schroedter, M., and Gesell, G.: Retrieval of aerosol optical depth and type in the boundary layer over land and ocean from simultaneous GOME spectrometer and ATSR-2 radiometer measurements -2 . Case study application and validation, J. Geophys. Res., 107(D21), 4770-4777, 2002 b.

Holzer-Popp, T., Schroedter-Homscheidt, M., Breitkreuz, H., Martynenko, D., and Klüser, L.: Improvements of synergetic aerosol retrieval for ENVISAT, Atmos. Chem. Phys., 8, 7651-7672, doi:10.5194/acp-8-7651-2008, 2008.

Hutchinson, K. D., Smith, S., and Faruqui, S.: The use of MODIS data and aerosol products for air quality prediction, Atmos. Environ., 38, 5057-5070, 2004

Jakobs, H. J., Tilmes, S., Heidegger, A., Nester, K, and Smiatek, G.: Short-term ozone forecasting with a network model system during Summer 1999, J. Atmos. Chem., 42, 23-40, 2002/

Jeuken, A. B. M., Eskes, H. J., van Velthoven, P. F. J., Kelder, H. M., and Hólm, E. V.: Assimilation of total ozone satellite measurements in a three-dimensional tracer transport model, J. Geophys. Res., 104(D5), 5551-5563, 1999.

Kavouras, I. G., Mihalopoulos, N., and Stephanou, E. G.: Formation of atmospheric particles from organic acids produced by forests, Nature, 395, 683-686, 1998.

Kawamura, K. and Sakaguchi, F.: Molecular distributions of water soluble dicarboxylic acids in marine aerosols over the Pacific Ocean including tropics, J. Geophys. Res., 104(D3), 3501-3509, 1999.

Kendall, M., Hamilton, R. S., Watt, J., and Williams, I. D.: Characterisation of selected speciated organic compounds associated with particulate matter in London, Atmos. Environ., 35, 24832495, 2001.

Kerminen, V.-M., Ojanen, C., Pakkanen, T., Hillamo, R., Aurela, M., and Meriläinen, J.: Low-molecular-weight dicarboxylic acids in an urban and rural atmosphere, J. Aerosol Sci, 31(3), 349-362, 2000.

Khattatov, B.V., Gille, J. C., Lyjak, L. V., Brasseur, G. P., Dvortsov, V. L., Roche, A. E., and Waters, J. W.: Assimilation of photochemically active species and a case analysis of UARS data, J. Geophys. Res., 104, 18715-18737, 1999.

Koch, S., Winterhalter, R., Uherek, E., Kolloff, A., Neeb, P., and Moortgat, G. K.: Formation of new particles in the gas-phase ozonolysis of monoterpenes, Atmos. Env., 34, 4031-4042, 2000.

Kokhanovsky, A. A., Bramstedt, K., von Hoyningen-Huene, W., and Burrows, J. P.: The intercomparison of top-of-atmosphere reflectivity measured by MERIS and SCIAMACHY in the spectral range of 443-865 nm, IEE Trans. Geosci. Rem. Sens. Lett., 4, 293-296, 2007.

Kriebel, K. T., Saunders, R. W., and Gesell, G.: Optical properties of clouds derived from fully cloudy AVHRR pixels, Beitr. Phys. Atmos., 62, 165-171, 1989.

Kriebel, K. T., Gesell, G., Kästner, M., and Mannstein, H.: The cloud analysis tool APOLLO: Improvements and validation, Int. J. Remote Sens., 24(12), 2389-2408, 2003.

Krivacsy, Z., Hoffer, A., Sarvari, Z., Temesi, D., Baltensperger, U., Nyeki, S., Weingartner, E., Kleefeld, S.,and Jennings, S. G.: Role of organic and black carbon in the chemical composition of atmospheric aerosol at European background sites, Atmos. Environ., 35, 6231-6244, 2001.

Kubatova, A., Vermeylen, R., Claeys, M., Cafmeyer, J., Maenhaut, W., Roberts, G., and Artaxo, P.: Carbonaceous aerosol characterization in the Amazon basin, Brazil: novel dicarboxylic acids and related compounds, Atmos. Environ., 34, 5037-5051, 2000.

Lahoz, W. A., Errera, Q., Swinbank, R., and Fonteyn, D.: Data assimilation of stratospheric constituents: a review, Atmos. Chem. Phys., 7, 5745-5773, doi:10.5194/acp-7-5745-2007, 2007a.

Lahoz, W. A., Geer, A. J., Bekki, S., Bormann, N., Ceccherini, S., Elbern, H., Errera, Q., Eskes, H. J., Fonteyn, D., Jackson, D. R., Khattatov, B., Marchand, M., Massart, S., Peuch, V.-H., Rharmili, S., Ridolfi, M., Segers, A., Talagrand, O., Thornton, H. E., Vik, A. F., and von Clarmann, T.: The Assimilation of Envisat data (ASSET) project, Atmos. Chem. Phys., 7, 1773-1796, doi:10.5194/acp-7-1773-2007, 2007 b.

Lamarque, J. F., Khattatov, B. V., Gille, J. C., and Brasseur, G. P.: Assimilation of measurements of air pollution from space (MAPS) CO in a global three-dimensional model, J. Geophys. Res., 104(D21), 26209-26218, 1999.

Lang, Q., Zhang, Q., and Jaffe, R.: Organic aerosols in the Miami area, USA: temporal variability of atmospheric particles and wet/dry deposition, Chemosphere, 47, 427-441, 2002.

Levelt, P. F., Khattatov, B. V., Gille, J. C., Brasseur, G. P., Tie, X. X., and Waters, J. W.: Assimilation of MLS ozone measurements in the global three-dimensional chemistry transport model ROSE, Geophys. Res. Lett., 25(24), 4493-4496, 1998.

Levy, R. C., Remer, L. A., Kleidman, R. G., Mattoo, S., Ichoku, C., Kahn, R., and Eck, T. F.: Global evaluation of the Collection 5 MODIS dark-target aerosol products over land, Atmos. Chem. Phys. Discuss., 10, 14815-14873, doi:10.5194/acpd-10-148152010, 2010.

Limbeck, A., Puxbaum, H., Otter, L., and Scholes, M. C.: Semivolatile behaviour of dicarboxylic acids and other polar organic species at a rural background site (Nylsvley, RSA), Atmos. Environ., 35, 1853-1862, 2001. 
Liu, D. C. and Nocedal, J.: On the limited memory BFGS method for large scale optimization, Math. Programm., 45, 503-528, 1989.

Loader, A., Mooney, D., and Coghlan, M.: UK Smoke and Sulphur Dioxide Network 2003, Report Nr. AEAT/ENV/R/1900/Issue 1, Juli 2005, AEA Technology plc., Netcen devision, Harwell Business Centre, Didcot, Oxon, OX11 0QJ, UK, 2005.

Lorenc, A.: A global three-dimensional multivariate statistical interpolation scheme, Mon. Weather Rev., 109, 701-721, 1986.

Martynenko, D., Schroedter-Homscheidt, M., Elbern, H., and Holzer-Popp, T.: Understanding the aerosol information content in multi-spectral reflectance measurements using a synergetic retrieval algorithm, Atmos. Meas. Tech., under review, 2010.

Memmesheimer, M., Hass, H., Tippke, J., and Ebel, A.: Modeling of episodic emission data for Europe with the EURAD emission model EEM, in: Proceedings of the International Speciality Conference Regional Photochemical Measurement and Modeling Studies, vol. 2, edited by: Ranzieri, A. and Solomon, P., Air and Waste Management Association, San Diego, USA, 495-499, 1995.

Memmesheimer, M., Friese, E., Ebel, A., Jakobs, H.J., Feldmann, H., Kessler, C., and Piekorz, G.: Long-Term Simulations of Particulate Matter in Europe on different scales using sequential nesting of a regional model, Journal of Environment and Pollution, 22(1-2), 108-132, 2004.

Meloni, D., di Sarra, A., Biavati, G., De Luisi, J. J., Monteleone, F., Pace, G., Piacentino, S., and Sferlazuzo, D. M.: Seasonal behavior of Saharan dust events at the Mediterranean Island of Lampedusa in the period 1999-2005, Atmos. Environ., 41, 3041-3056, 2007.

Monahan, E. C., Spiel, D. E., Davidson, and K. L.: Oceanic Whitecaps, edited by: Monahan, E. C., Mac Niocaill, G., Reidel, D., 167-174, 1986.

Nickovich, S., A. Papadopoulos, O. Kakaliagou, and Kallos, G.: Model for prediction of desert dust cycle in the atmosphere, J. Geophys. Res., 106, 18113-18130, 2001.

Niu, T., Gong, S. L., Zhu, G. F., Liu, H. L., Hu, X. Q., Zhou, C. H., and Wang, Y. Q.: Data assimilation of dust aerosol observations for the CUACE/dust forecasting system, Atmos. Chem. Phys., 8, 3473-3482, doi:10.5194/acp-8-3473-2008, 2008.

Ouimette, J.R., Flagan, R.C.: The extinction coefficient of multicomponent aerosols, Atmos. Environ., 16(10), 2405-2419, 1982

Papayannis, A., Amiridis, V., Mona, L., Tsaknakis, G., Balis, D., Bösenberg, J., Chaikovski, A., De Tomasi, F., Grigorov, I., Mattis, I., Mitev, V., Müller, D., Nickovic, S., Perez, C., Pietruczuk, A., Pisani, G., Ravetta, F., Rizi, V., Sicard, M., Trickl, T., Wiegner, M., Gerding, M., Mamouri, R. E., D’Amico, G., and Pappalardo, G.: Systematic lidar observations of Saharan dust over Europe in the frame of EARLINET (2000-2002), J. Geophys. Res., 113, D10204, doi:10.1029/2007JD009028, 2008.

Pio, C., Alves, C., and Duarte, A.: Organic components of aerosols in a forested area of central Greece, Atmos. Environ., 35, 389401, 2001.

Rasch, P. J., Barth, M. C., Kiehl, J. T., Schwartz, S. E., and Benkovitz, C. M.: A description of the global sulfur cycle and its controlling processes in the National Center for Atmospheric Research Community climate Model, Version 3, J. Geophys. Res., 105, 1367-1385, 2000.

Rasch, P. J., Collins, W. D., and Eaton, B. E.: Understanding the
Indian Ocean Experiment (INDOEX) aerosol distributions with an aerosol assimilation, J. Geophys. Res., 106(D7), 7337-7355, 2001.

Rasch, P. J., Mahowald, N. M., and Eaton, B. E.: Representations of transport, convection, and the hydrologic cycle in chemical transport models: Implications for the modeling of short-lived and soluble species, J. Geophys. Res., 102(28), 28127-28138, 1997.

Roehrl, A. and Lammel, G.: Low-Molecular weight dicarboxylic acids and glyoxylic acid: seasonal and air mass characteristics, Environ. Sci. Technol., 35, 95-101, 2001.

Sartelet, K. N., Debry, E., Fahey, K., Roustan, Y., Tombette, M., and Sportisse, B.: Simulation of aerosols and gas-phase species over Europe with the POLYPHEMUS system - Part 1: Model-to-data comparison for 2001, Atmos. Environ., 41, 6116-6131, 2007.

Saxena, P., Hildemann, L. M., McMurry, P. H., and Seinfeld, J. H.: Organics alter hygroscopic behaviour of atmospheric particles, J. Geophys. Res., 100(D9), 18755-18770, 1995.

Schell, B., Ackermann, I. J., Hass, H., Binkowski, F. S., and Ebel, A.: Modeling the formation of secondary organic aerosol within a comprehensive air quality model system, J. Geophys. Res., 106(D22), 28275-28293, 2001.

Schnaiter, M., Horvath, H., Möhler, O., Naumann, K.-H., Saathoff, H., and Schöck, O. W.: UV-VIS-NIR spectral optical properties of soot and soot-containing aerosols, J. Aerosol Sci., 34, 14211444, 2003.

Schroedter-Homscheidt, M.: Beobachtungsoperator zur Assimilation satelliten-basierter Messungen verschiedener Aerosoltypen in ein Chemie-Transportmodell, $\mathrm{PhD}$ thesis, Universität zu Köln, Germany, 2009.

Seinfeld, J. H. and Pandis, S. N.: Atmospheric chemistry and physics: From air pollution to climate change, John Wiley \& Sons, New York, USA, 1998.

Tegen, I. and Fung, I.: Modeling of mineral dust in the atmosphere: Sources, transport, and optical thickness, J. Geophys. Res., 99(D11), 22897-22914, 1994.

Tegen, I. Hollrig, P., Chin, M., Fung, I., Jacob, D., and Penner, J.: Contribution of different aerosol species to the global aerosol extinction optical thickness: Estimates from model results, J. Geophys. Res., 102(D20), 23895-23915, 1997.

Tsapakis, M., Lagoudaki, E., Stephanou, E. G., Kavouras, I. G., Koutrakis, P., Oyola, P., and von Baer, D.: The composition and sources of $\mathrm{PM}_{2.5}$ organic aerosol in two urban areas of Chile, Atmos. Environ., 36, 3851-3863, 2002.

Van Loon, M., Builtjes, P. J., and Segers, A.: Data assimilation of ozone in the atmospheric transport chemistry model LOTOS, Env. Mod. and Softw., 15, 603-609, 2000.

Van Velthoven, P., Builtjes, P., and Schaap, M.: An assessment of assimilation techniques presently available, as well as an assessment of the requirements for a fully functional aerosol assimilation system, deliverable report D21 of EU DAEDALUS project, availble at: http://www-loa.univ-lille1.fr/ Daedalus/Daedalus/index.html, 2004.

Vautard, R., Builtjes, P.H., Thunis, P., Cuvelier, C., Bedogni, M., Bessagnet, B., Honore, C., Moussiopoulus, N., Pirovano, G., Schaap, M., Stern, R., Tarrasón, L., and Wind, P.: Evaluation and intercomparison of Ozone and $\mathrm{PM}_{10}$ simulations by several chemistry transport models over four European cities within the CityDelta project, Atmos. Environ., 41, 173-188, 2007. 
Verver, G. H. L., Henzing, J. S., De Leeuw, G., Robles-Gonzalez, C., van and Velthoven, P. F. J.: Aerosol retrieval and assimilation (ARIA), final report, KNMI publication 200, ISBN 90-3692223-2, 2002.

Wang, G., Niu, S., Liu, C., and Wang, L.: Identification of dicarboxylic acids and aldehydes of $\mathrm{PM}_{10}$ and $\mathrm{PM}_{2.5}$ aerosols in Nanjing, China, Atmos. Environ., 36, 1941-1950, 2002.

Wang, J., Christopher, S. A., Reid, J. S., Maring, H., Savoie, D., Holben, B. H., Livingston, J. M., Russell, P., and Yang, S. K.: GOES 8 retrieval of dust aerosol optical thickness over the Atlantic Ocean during PRIDE, J. Geophys. Res., 108, doi:10.1029/2002JD002494, 2003.

Wang, J., Nair, U. S., and Christopher, S. A.: Assimilation of satellite-derived aerosol optical thickness and online integration of aerosol radiative effects in a mesoscale model, 13th Conference on Satellite Meteorology and Oceanography, 20-23 September 2004, Norfolk, USA, 2004a.

Wang, J., Nair, U., and Christopher, S.: GOES-8 aerosol optical thickness assimilation in a mesoscale model: Online integration of aerosol radiative effects, J. Geophys. Res., 109, D23203, doi:2004JD004827, 2004b.

Warscheid, B. and Hoffmann, T.: On-line measurements of alphapinene ozonolysis products using an atmospheric pressure chemical ionisation ion-trap mass spectrometer, Atmos. Environ., 35, 2927-2940, 2001.
Weaver, A. and Courtier, P.: Correlation modelling on the sphere using a generalized diffusion equation, Q. J. Roy. Meteor. Soc., 127, 1815-1846, 2001.

Whitby, K. T. and Sverdrup, G. M.: California aerosols: Their physical and chemical characteristics, Adv. Environ. Sci. Technol., 10, 477-517, 1973.

Yassaa, N., Meklati, B. Y., Cecinato, A., and Marino, F.: Chemical characteristics of organic aerosol in Bab-Ezzouar (Algiers), Contribution of bituminous product manufacture, Chemosphere, 45, 315-322, 2001.

Yu, H., Dickinson, R. E., Chin, M., Kaufman, Y. J., Holben, B. N., Geogdzhayev, I. V., and Mishchenko, M. I.: Annual cycle of global distributions of aerosol optical depth from integration of MODIS retrievals and GOCART model simulations, J. Geophys. Res., 108(D3), 4128, doi:10.1029/2002JD002717, 2003.

Yu, S.: Role of organic acids (formic, acetic, pyruvic and oxalic) in the formation of cloud condensation nuclei $(\mathrm{CCN})$ : a review, Atmos. Res., 53, 185-217, 2000. 